This item was submitted to Loughborough's Research Repository by the author.

Items in Figshare are protected by copyright, with all rights reserved, unless otherwise indicated.

\title{
Getting a grip
}

PLEASE CITE THE PUBLISHED VERSION

http://dx.doi.org/10.1177/106480460100900204

\section{PUBLISHER}

Sage / @ Human Factors and Ergonomics Society

\section{VERSION}

AM (Accepted Manuscript)

\section{PUBLISHER STATEMENT}

This work is made available according to the conditions of the Creative Commons Attribution-NonCommercialNoDerivatives 4.0 International (CC BY-NC-ND 4.0) licence. Full details of this licence are available at: https://creativecommons.org/licenses/by-nc-nd/4.0/

\section{LICENCE}

CC BY-NC-ND 4.0

\section{REPOSITORY RECORD}

Torrens, George E., Deana McDonagh-Philp, and Anne Newman. 2019. "Getting a Grip”. figshare. https://hdl.handle.net/2134/15763. 


\section{Getting a grip: The application of a model of hand and object}

\section{interaction.}

George Torrens, Deana McDonagh-Philp and Anne Newman

Contact

G E Torrens

Department of Design and Technology, Loughborough University, Loughborough, Leicestershire, LE11 3 3TU Tel. $1509 \quad 222 \quad 664$ Fax. $1509 \quad 223 \quad 999$ email g.e.torrens@1boro.ac.uk

\section{Introduction}

The way in which we control and interact with our environment is most often through our hands. Whilst there are many references that provide explanations of the physical interaction between hand and object during a task, they still fall short of a simplified model. Guidelines and performance specifications that can be easily applied by practising industrial designers and other members of a product development team are vital to an effective outcome. The model of hand and object interaction (HOI) described here uses current clinical and ergonomic measurement techniques such as task analysis, observation, interview, focus groups, questionnaires, anthropometrics and measurement of range of movement and grip strength. As well as these, further measurements of finger friction and finger compliance, or finger stiffness are undertaken. 
This user-centred design approach was employed by the authors to elicit user needs and aspirations alongside physical functionality (effectiveness). It provides validation of the research outcomes to support new product development and a more holistic and evidence based approach for Industrial Designers (McDonagh-Philp, Lebbon and Torrens 1999). The emphasis on manual use of products requires a detailed description of HOI within this case study to provide criteria for the evaluation of existing and new cutlery products.

\section{Hand Object Interaction Model}

The following model is based upon eight years of research into the area of hand and object interaction (Brown, Torrens and Wright 1992, Torrens and Gyi 1999). HOI in this paper, focuses upon the physical interaction between the hand and the task object, rather than the cognitive interaction. The measurements described in this paper reflect the emphasis upon characterising the physical attributes of the hand and relating them to a defined physical interaction with an object, during the performance of a given task. The model is based upon three levels of physical interaction, macro, intermediate, and micro interaction. Figures 1 and 2 show the three levels of interaction and the forces they resist. It should be noted that micro and intermediate interaction resist shear forces in parallel with the palmar surface, whereas macro interaction resists forces that are perpendicular to the palmar surface. 

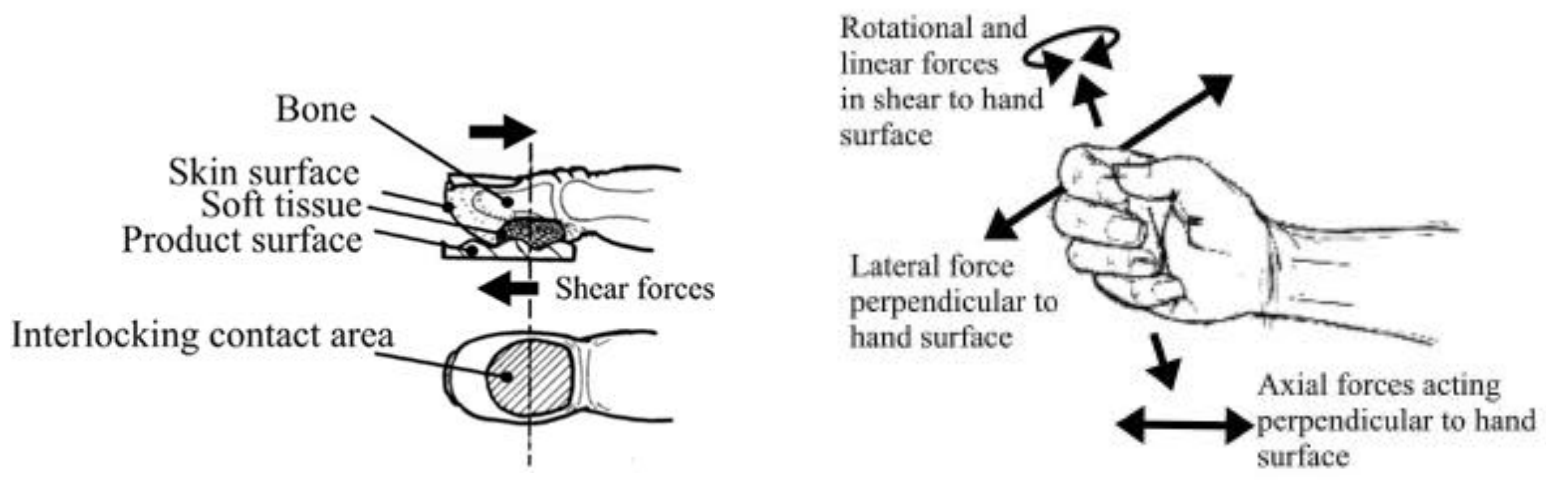

Figure 1. Micro interaction is the friction Figure 2. Macro interaction involves the structure between the skin and product surface materials. of the hand (bone, joints and muscles) Intermediate interaction involves the soft tissues interlocking with the shape of the product. This underlying the palm face interlocking with level of interaction has been found to work at all surface details of a product to provide a levels of force, but primarily involved in tasks mechanical interlock beyond skin friction. These over 20 Newtons force.

two levels of interaction have been found to work

best at less than 20 Newtons force.

Table 1 is a comprehensive overview of hand and object interaction, measurements taken and their outcomes. Selected individual measurements may be used in isolation that may be adequate to validate hand characteristics and interaction performance. The choice of measurements to be taken may depend upon project constraints such as time-scales, user group characteristics, funding and available resources (e.g. staffing).

The following case study provides an example of the application of some of the measurements shown in Table 1. The physical measurements taken at a given moment within a task or series of tasks can vary considerably within an individual. This is because the physiological and psychological state of an individual is constantly changing, mainly due 
to external influences such as stress (e.g. needing to complete a job urgently, for example), humidity, temperature and vibration (including noise). The physiological changes that affect grip can be measured through heart rate, blood pressure, skin or body temperature, and skin humidity. The external influences such as pressure to perform a task, environmental temperature, noise/vibration and humidity can also be measured to compare with the measurements from a subject. Such a comprehensive set of measurements of a given task enables a more detailed characterisation of a subject and the task they are performing. 
Table 1. Shows an overview of hand and object interaction and related test methods

\section{Hand/body characteristics \\ Object Characteristics \\ Equipment \\ Outcome}

Micro interaction

Skin friction; skin moisture; stress; state of physical exertion; heart rate; blood pressure; blood flow;

surface pressure

Skin and soft tissue friction

Intermediate

interaction

Macro interaction

\section{segment position (grip}

pattern); joint capsule

integrity; skeletal integrity;

tendon integrity; range of

movement; muscle bulk;

temperature; humidity;

stress; heart rate; blood

pressure and flow; surface

pressure; Anthropometrics
Friction meter;

thermocouple; blood flow

meter; humidity meter

(galvanic resistance)

(sharp)

Surface features; surface material; surface finish;

surface temperature

\section{Compliance meter;}

thermocouple; blood flow

meter; humidity meter

Object handle/ grip size

shape; surface temperature;

edge detail (sharp)
Skin performance (friction), related to skin and underlying soft tissue compliance. Pressure $(\mathrm{Pa})$ at points on the surface of the hand, finger temperature and surface moisture

Compliance characteristics of skin and underlying soft tissues that enable mechanical interlocking to occur related to finger friction. Excel file; hand and finger surface pressure, finger temperature and surface moisture

CODA, Goniometer; video; stadiometer; anthropometer

The ability of the hand to mechanically interlock with an object shape, optimising soft tissue and skin friction. Excel file, $x, y, z$ co-ordinates related to time, force (vector and resultant, torque), hand surface pressure, surface temperature and surface moisture 


\section{Case Study}

Many of the available assistive technology (AT) cutlery products have originated from clinical studies or individual clinicians' expertise. AT products are those where the product supports an individual in daily livings tasks, such as glasses for reading, or a walking cane. However, within the United Kingdom and Northern Ireland (UK\&NI) AT products are often categorised as wheelchairs, lifting hoist, hearing aids or environmental controllers. Though these products satisfy utilitarian-functional needs, it is clear that the products do not always meet users' cultural and social aspirations. Industrial Design brings together the physical functionality, social and cultural function (i.e. desirability), through a user-centred design approach. Nottingham Rehab Supplies Limited (NRSL) commissioned design research into cutlery for users with limited grip and dexterity. The cutlery was to be marketed to a large user group within the UK\&NI, Europe and America. The cutlery reviewed reflected the commercially available ranges in the UK\&NI. Many of these are also available in Continental Europe and the United States of America. The pilot study involved volunteer subjects from the Loughborough (Leicestershire, UK) area, who had a range of different musculoskeletal and neuromuscular diseases. The sample group reflected the larger population who were likely to require AT cutlery. The contacts were obtained through National, Regional and Branch offices of special interest groups within the UK, (e.g. Age Concern, Arthritis Care, and Community Groups).

The selection of seven individuals for the initial pilot study reflected the medical conditions that induce weak grip or limit dexterity within a person. Table 2 . shows the hands of the seven individuals and an outline of their medical condition. Initially, the assessment involved the use of a grip dynamometer and a simple task. Subjects were accepted if they 
had grip strength of less than 150 Newtons in their right hand, or if they could not touch one or more of their fingers to their thumb of the same hand, or make a fist. The subjects were asked to present their own cutlery. These products provided a benchmark for comparison with a range of 7 sets of cutlery (see Table 3 ). These sets of cutlery were chosen to represent the range of products currently available for users who have limited dexterity and grip strength.

Individuals were asked to provide a subjective rating (on a scale of 1-5) for each set of cutlery, including their personal use cutlery (1, very good; 2, good; 3, adequate; 4, poor; 5, very poor). The ratings, or scores, covered both physical functions, usability for example, and design detailing such as colour, shape and ease of cleaning. As part of the evaluation they were asked to demonstrate how they would normally use the products whilst simulating the cutting of a piece of rubber that represented a piece of lean meat. During a rating exercise, the researcher noted any additional comments made by the subjects relating to social and cultural issues. The rating scale included comfort, usability, weight and design of utensil head. The appearance value of the handle (e.g. colour, shape, size, style and ease of cleaning) were also evaluated with each subject.

The scores from each individual were then combined and averaged to provide a group score for each heading (e.g. colour, style, usability). The group scores from each of the seven headings were the combined and averaged to provide an overall score. (See Table 4). 
Table 2. Existing products used for product design audit and benchmarking

\begin{tabular}{|c|c|c|c|}
\hline Sample & & Name & Supplier \\
\hline A & Queens & Smith \& Nephew Homecraft \\
\hline B & cutlery & Limited \\
\hline $\mathrm{C}$ & & AMEFA & Nottingham Rehab Limted \\
\hline $\mathrm{D}$ & & & \\
\hline $\mathrm{F}$ & & Caring & Nottingham Rehab Limted \\
\hline
\end{tabular}

The dimensions of the cutlery were measured to provide comparative analysis. The length of handle and centre of gravity were measured (see Figure 3). The centre of gravity was measured from the distal (furthest point away from the body when held) end of the handle, along the handle proximally (towards the body). This provided an indication of how the handle would behave when held at this point in the hand. 
In order to optimise the three levels of interaction, the forces resisted by the hand through the handle of the sample cutlery products were considered. During early interviews with users, it was observed that only a limited number of conventional grip patterns were attempted. When using a knife, fork and spoon, the knife was observed to generate the most difficulty. The authors considered that cutting meat products was the most demanding task to be undertaken using cutlery. Based on observation of cutting tasks and existing references (Bobjer 1996), forces forward and backward along the line of the forearm were the largest generated. A test of the forces involved during cutting was undertaken using an instrumented beam (strain gauge) and force sensor. This method was an adaptation of one previously used to measure finger friction (Torrens 1997). The outcome of this measurement was shown as a coefficient of friction. Photographs were taken of each subject using each set of cutlery, (see Table 4). This enabled grip and upper limb posture to be reviewed and considered within the next phase of development.

\section{Outcomes}

Tables 3 and 4 show the outcomes recorded from the seven subjects using the seven sample products. Table 5 shows the overall ratings achieved by each set of cutlery. 
Table 3. Shows The hands of each subject and their medical condition

\begin{tabular}{|c|c|}
\hline Subject & Description of medical condition \\
\hline 1 & $\begin{array}{l}\text { Tetraplaegic C6 Complete. Injured in 1984, contracture } \\
\text { of right hand fingers enables grip through wrist flexion. }\end{array}$ \\
\hline 2 & $\begin{array}{l}\text { Rheumatoid Arthritis (RA), had disease for } 40 \text { years, } \\
\text { affects most joints. }\end{array}$ \\
\hline 3 & $\begin{array}{c}\text { RA, in most joints, severe Ulna deviation, contracture of } \\
\text { finger tendons. }\end{array}$ \\
\hline 4 & $\begin{array}{l}\text { Osteoarthritis of the hands and upper limb, enlarged } \\
\text { knuckle (MCP) joints, frail condition. }\end{array}$ \\
\hline 5 & $\begin{array}{l}\text { Spinal infarction (form of Stroke) in the spine, injured in } \\
\text { 1987, diabetes, general loss of upper limb function, } \\
\text { limited haptic perception. }\end{array}$ \\
\hline 6 & $\begin{array}{l}\text { Skin disease (itching), left hand index finger fixed in } \\
\text { extension, frail condition. }\end{array}$ \\
\hline 7 & $\begin{array}{l}\text { RA in all joints, had disease for } 16 \text { years, restricted } \\
\text { finger and upper limb movement. }\end{array}$ \\
\hline
\end{tabular}


Table 4. Shows subject 2 using the range of cutlery evaluated. From the above details, it can be seen that this person (subject 2 ), when using a knife and fork, approached the plate with the utensils at a steep vertical angle. This is to maximize the downward force applied through their hands. Knife,

fork and spoon are balanced in the hand when not in active use.

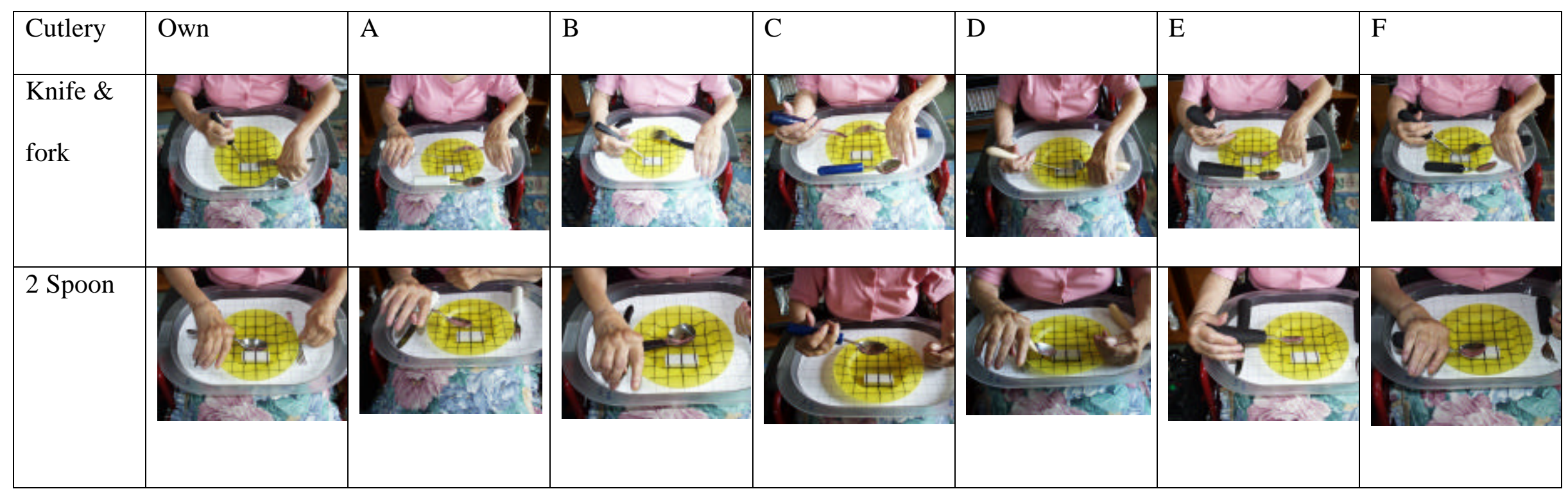


The sample group for this pilot provided a broad spectrum of medical conditions, age and socio-economic backgrounds. Five subjects lived in single level accommodation (i.e. no stairs and lift access), two subjects lived in apartments with care worker support. The mean grip strength was extremely low, not exceeding 50 Newtons. Three of the subjects could not hold the grip dynamometer and 5 could not make a fist with their right hand.

The product design auditing of the 7 sets of cutlery produced a range of results. The range of weight and handle length varies by a substantial margin, within the samples tested. Weight ranged from $27.64 \mathrm{~g}$ to $88.55 \mathrm{~g}$. Overall length ranged from $188 \mathrm{~mm}$ to $230 \mathrm{~mm}$. Handle length ranged from $80 \mathrm{~mm}$ to $103 \mathrm{~mm}$. The centre of gravity ranged from $-6 \mathrm{~mm}$ to $36 \mathrm{~mm}$ from the distal end of the handle, where a minus value indicates the point is beyond the distal end of the handle (See Figure 3). Cutlery handles of sample E were found to have the highest coefficient of friction at 2.58. This is primarily due to the foamed elastomer handle material. Knife samples D and F were found to be the most efficient at cutting the meat block. The knife D had a blade that was serrated, knife F was plain. The other knives all had serrated blades. The angle of the blade may have had more affect on the performance than the blade serration. The other four knives all had conventional shaped blades. Knives D and F had a steeply angled blades at the front $\left(\mathrm{D}=25^{\circ}, \mathrm{F}=30^{\circ}\right)$.

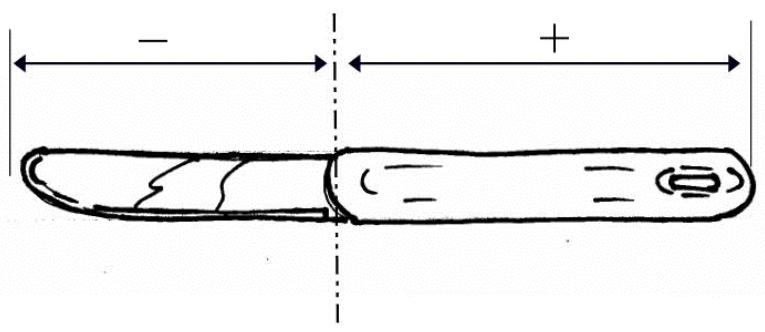

Figure 3. Shows the measurement point of the centre of gravity of a utensil (in this case a knife) where negative is a Centre of Gravity (C. of G.) beyond the handle. 
Table 5. Overall functional detail percentage

\begin{tabular}{llllllll}
\hline Cutlery detail & Own & A & B & C & D & E & F \\
\hline Comfort & 55.1 & 73.3 & 92.9 & 90.3 & 68.1 & 68.6 & 59.6 \\
Usability & 56.8 & 77.1 & 90.9 & 89.4 & 69.1 & 82.7 & 71.8 \\
Weight & 52.5 & 56.2 & 67 & 79.6 & 57 & 58.9 & 61.3 \\
Utensil head & 56 & 62.9 & 78.1 & 76.3 & 61.3 & 77.5 & 66.2 \\
\hline Cutlery detail & Own & A & B & C & D & E & F \\
\hline Handle colour & 55 & 73.3 & 71.4 & 85.7 & 73.3 & 74.3 & 77.1 \\
Handle shape & 56 & 74.3 & 88.6 & 94.3 & 74.3 & 86.6 & 73.3 \\
Handle size & 48 & 74.3 & 77.1 & 94.3 & 71.4 & 90 & 76.6 \\
Style & 52 & 71.4 & 82.9 & 91.4 & 62.9 & 85.7 & 73.3 \\
Ease of cleaning & 48 & 54.3 & 60 & 74.3 & 62.9 & 82.9 & 96.7 \\
\hline Overall rating & 54.3 & 67.2 & 80.7 & 85 & 65.1 & 74.9 & 68.4 \\
\hline
\end{tabular}

The values shown in Tables 5 and 6 are a composite value produced by combining the rating given by each of the seven subjects for each question. A value of over 80 indicated a strong dislike of the cutlery product. A value less than 60 indicated that the subjects liked the cutlery product sample. The scale provides an indication or a trend of opinions from within the sample group. In Table 5 it can be seen that there was a noticeable dislike for the samples B, $\mathrm{C}$ and E. All three had high overall rating values and individual values. Sample A was well liked for its perceived weight and ease of cleaning. The user group disliked sample cutlery sets B and C, with dissatisfaction expressed about the defined aspects of all other sample sets. The cutting forces of between 2 and 4 Newtons involved in meat cutting using a knife are small compared to lifting a coffee pot, for example. 
Table 6. The overall rating of each cutlery set evaluated by the seven subjects. Note the overall performance of set A (Queens Cutlery), D (Caring Cutlery) and F (Goodgrips) when compared to the subject's own cutlery. The lower the rating the more satisfied the user group with the cutlery set overall.

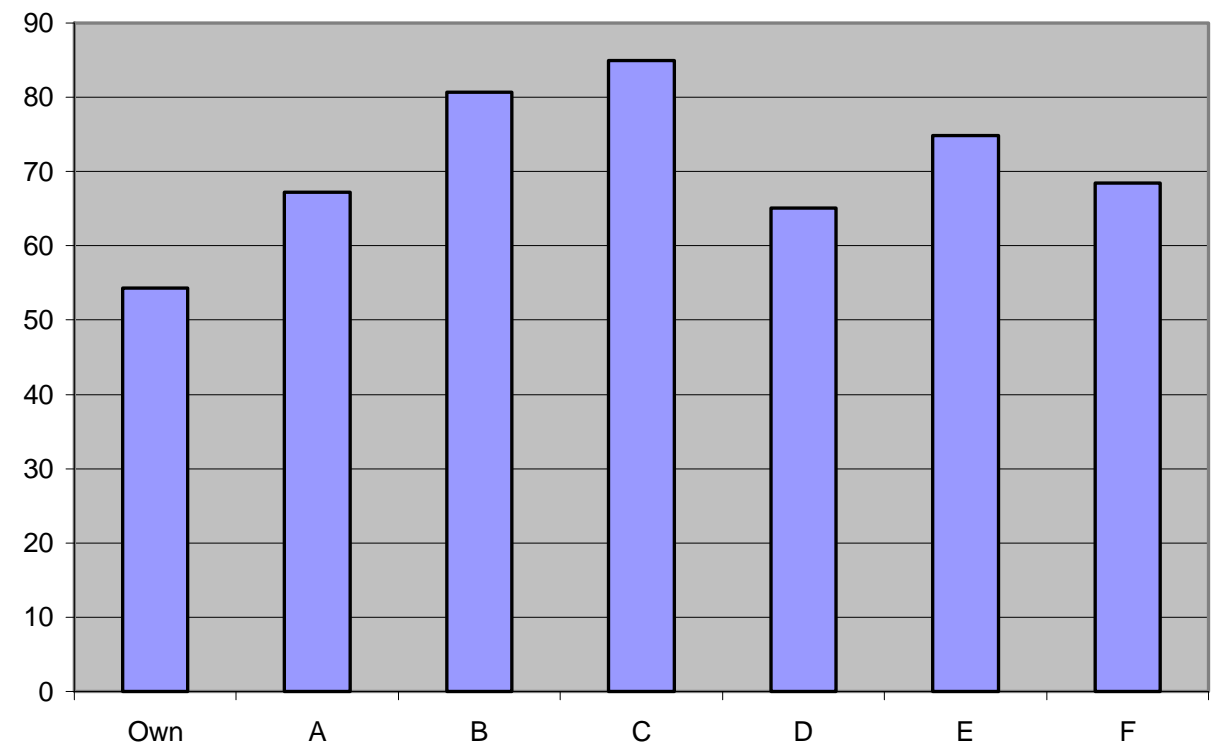

\section{Points to consider}

The subjects interviewed during this evaluation highlighted a number of problems found when using the commercially available ranges of cutlery. Functional and physical problems were detailed, alongside the users' visual aspirations for this product, and a cutlery specification developed to fulfil these deficiencies, as shown in Table 7 below. Whilst such a small sample survey of opinions and observed abilities should not be taken as a representation of the UK\&NI population as a whole, in the absence of accessible information it provides product developers with some guidance on the points to consider. 
Table 7. Subject feedback on cutlery samples

Current cutlery deficiencies

Specification for design solution

- Handles too large in diameter to hold - A handle with a thin section to enable the (samples A, C, D and E were over 30mm user to jam the utensil between fingers. wide).

- Handles with a ridge between the utensil

- Handle surface inadequate in assisting grip head and the handle and at the base of the through skin friction. handle to stop the hand slipping on to the

- Handle shapes incorrect for the majority of blade or off the handle during cutting. users interviewed.

- High friction handle material should be

- Centre of gravity of some cutlery used on the handle. incorrectly positioned (sample E was very

- The cross-section of the handle should be utensil head heavy). faceted, with the main area of grip smooth

- Length of the knife blade was found to be to avoid high pressure points.

as long as handle, reducing possible

- The knife blade should be angled, if leverage applied by the user through the possible. handle (all knife samples were around 50/50

- The handle should to be perceived by the handle/blade). user to be easy to clean.

- Poor styling.

- The handle should be machine washable

- Poor build quality. and avoid dirt traps.

- Appearing to be difficult to clean.

Based upon the initial findings, concept designs were produced using the CAD/CAM and injection moulding facilities within the Department (see Figures 3 and 4). The new designs incorporated many of the needs and aspirations expressed by those involved in the cutlery evaluation (see Table 8). 
Table8. Details of new cutlery product design specification (PDS).

New cutlery design specification

- The new cutlery has been designed to be inconspicuous when used in public places; it looks like conventional kitchen-grade cutlery.

- The black handle colour was chosen to reduce visually the overall handle size.

- The conventional handle shape and steel utensil head make it acceptable to other family members and friends (inclusive design).

- The handles are all the same shape, providing a strong identity to the set and reducing production costs.

- The handles are injection moulded over the steel utensil head to avoid dirt traps and all materials used are dish-washable.
- The flattened hexagonal handle section is large enough to enable a finger to be comfortably pressed on to the edge of the knife, or jammed, (cleat-like), into the crotch of the thumb and index finger.

- Ridges and dimples have been avoided because they cause discomfort to the target users as they often have poor skin quality due to their medical condition.

- The high friction elastomer covering on the handle provides an effective grip to the skin surface.

- The flared sections to the front and back of the handle length provide more stability against the utensil turning in the hand.

- The flared sections also stop the hand sliding off the handle front or back.

- The new designs are lightweight for ease of handling. 
The prototypes (Figures 4 and 5) were taken back to the subjects for evaluation. A cycle of evaluation, feedback, reflection and refinement was undertaken on a further two occasions and with a larger number of subjects. The final design is now being tooled for production and will be commercially available through the Nottingham Rehab Supplies Limited from late 2000.

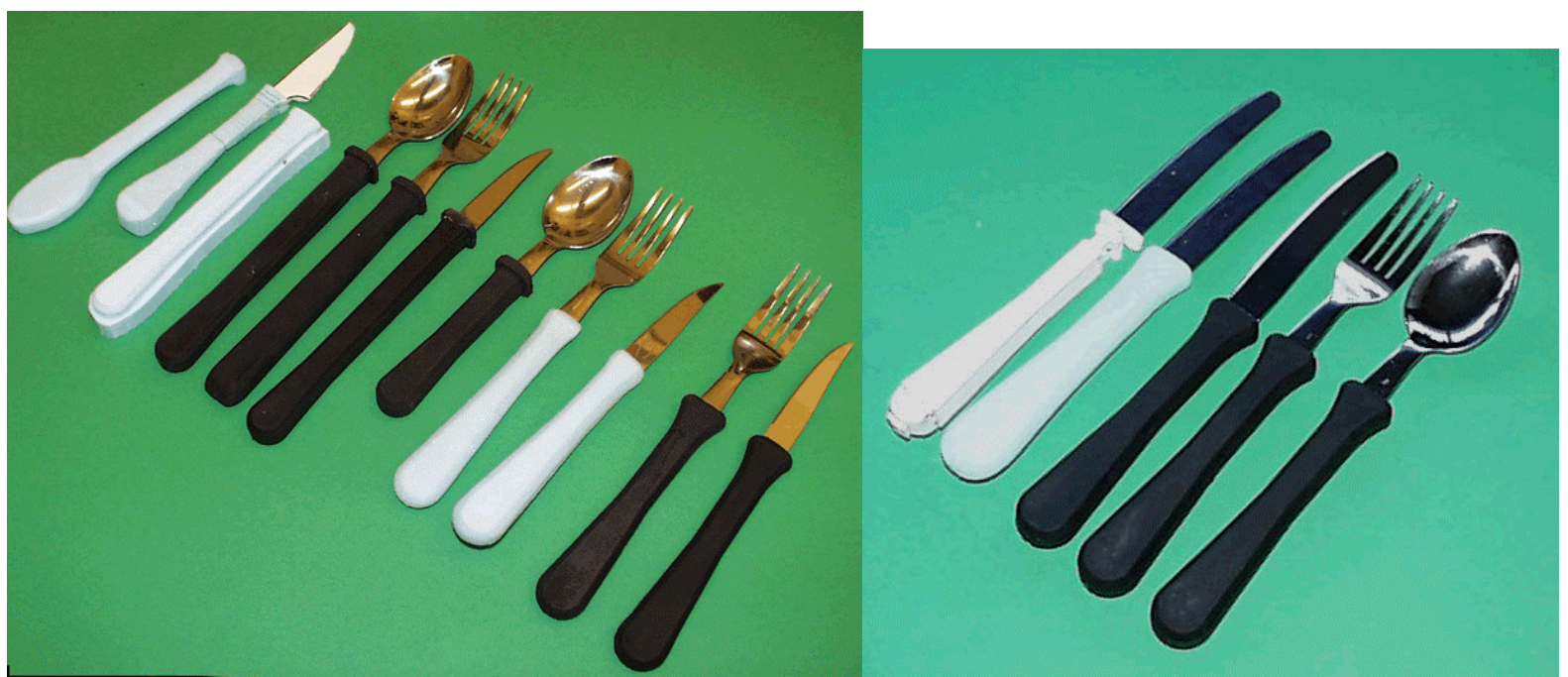

Figures 4 and 5 Show prototype cutlery development and the final pre-production design solution

\section{References}

Bobjer O (1989) Ergonomic Knives, Advances in Industrial Ergonomics and Safety I, Edited by A Mital, London: Taylor \& Francis pp 291-298.

Brown F R, Torrens G E, and Wright D K (1992) Research into optimising hand and body function for tasks in everyday living: the development of a range of "easy use" saucepan handles; In Bracale M. and Denoth F. (ed), Number 1, Medicon '92, Proceedings of the VI 
Mediterranean conference on medical and biological engineering (Associazione Italiana di Medica e Biologica, Napoli) pp549-553.

Torrens G E (1995) Designing for Physical Disability: A Discussion of Research and Development Methods Through to a Commercial Conclusion, Designing Interfaces: Inaugural Conference of the European Academy of Design, 1, Cooper R. (ed), University College Salford: University College, Salford ISBN 0952566613.

Torrens G E (1997) What is the optimum surface feature? Contemporary Ergonomics, Robertson S A (ed), London: Taylor \& Francis pp 314-319.

McDonagh-Philp D C, Lebbon C. and Torrens G E (1999) An evidence based design method within a user-centred design approach, Proceedings of The 4th Asian Design Conference International Symposium on Design Science, The Program Committee, Nagaoka, Japan, ISBN 4-9980 776-0-0, [CD-ROM].

Torrens G E and Gyi D E (1999) Towards the integrated measurement of hand and object interaction, Proceedings of the 7th International Conference on Product Safety Research, US Consumer Product Safety Commission, Washington, USA pp 217-226, ISBN 90-6788-2518. 